\title{
Efficacy and safety of haloperidol versus atypical antipsychotic medications in the treatment of delirium
}

Hyung-Jun Yoon ${ }^{1,2}$, Kyoung-Min Park², Won-Jung Choi ${ }^{1,2}$, Soo-Hee Choi ${ }^{2}$, Jin-Young Park ${ }^{1,2}$, Jae-Jin Kim ${ }^{1,2}$ and Jeong-Ho Seok ${ }^{1,2^{*}}$

\begin{abstract}
Background: Most previous studies on the efficacy of antipsychotic medication for the treatment of delirium have reported that there is no significant difference between typical and atypical antipsychotic medications. It is known, however, that older age might be a predictor of poor response to antipsychotics in the treatment of delirium. The objective of this study was to compare the efficacy and safety of haloperidol versus three atypical antipsychotic medications (risperidone, olanzapine, and quetiapine) for the treatment of delirium with consideration of patient age.

Methods: This study was a 6-day, prospective, comparative clinical observational study of haloperidol versus atypical antipsychotic medications (risperidone, olanzapine, and quetiapine) in patients with delirium at a tertiary level hospital. The subjects were referred to the consultation-liaison psychiatric service for management of delirium and were screened before enrollment in this study. A total of 80 subjects were assigned to receive either haloperidol $(N=23)$, risperidone ( $N=21)$, olanzapine $(N=18)$, or quetiapine $(N=18)$. The efficacy was evaluated using the Korean version of the Delirium Rating Scale-Revised-98 (DRS-K) and the Korean version of the Mini Mental Status Examination (K-MMSE). The safety was evaluated by the Udvalg Kliniske Undersogelser side effect rating scale.

Results: There were no significant differences in mean DRS-K severity or K-MMSE scores among the four groups at baseline. In all groups, the DRS-K severity score decreased and the K-MMSE score increased significantly over the study period. However, there were no significant differences in the improvement of DRS-K or K-MMSE scores among the four groups. Similarly, cognitive and non-cognitive subscale DRS-K scores decreased regardless of the treatment group. The treatment response rate was lower in patients over 75 years old than in patients under 75 years old. Particularly, the response rate to olanzapine was poorer in the older age group. Fifteen subjects experienced a few adverse events, but there were no significant differences in adverse event profiles among the four groups.
\end{abstract}

Conclusions: Haloperidol, risperidone, olanzapine, and quetiapine were equally efficacious and safe in the treatment of delirium. However, age is a factor that needs to be considered when making a choice of antipsychotic medication for the treatment of delirium.

Trial registration: Clinical Research Information Service, Republic of Korea, (http://cris.nih.go.kr/cris/en/search/basic_search. jsp, Registered Trial No. KCT0000632).

Keywords: Delirium, Haloperidol, Risperidone, Olanzapine, Quetiapine

\footnotetext{
* Correspondence: JOHNSTEIN@yuhs.ac

${ }^{1}$ Institutional address Department of Psychiatry and Institute of Behavioral

Science in Medicine, Yonsei University College of Medicine, 50 Yonsei-ro,

Seoul 120-752 Seodaemun-gu, Korea

${ }^{2}$ Institute of Behavioral Science in Medicine, Yonsei University College of

Medicine, Seoul, Korea
}

\section{Biomed Central}

(c) 2013 Yoon et al.; licensee BioMed Central Ltd. This is an Open Access article distributed under the terms of the Creative Commons Attribution License (http://creativecommons.org/licenses/by/2.0), which permits unrestricted use, distribution, and reproduction in any medium, provided the original work is properly cited. 


\section{Background}

Delirium is a common, complex neuropsychiatric disorder with a high prevalence among elderly hospitalized patients [1-3], postsurgical patients [4,5], and cancer patients [6-8] in advanced stages of illness. Typically, delirium shows an abrupt, rapid onset and a fluctuating course $[9,10]$. The core features of delirium consist of disturbances in cognitive function such as attention, memory, thought, and language $[9,10]$. However, its clinical presentation can be highly variable with a broad range of associated non-cognitive, behavioral symptoms that reflect the influence of distinct etiologies, medical comorbidities, or pharmacological treatments $[10,11]$.

In hospitalized elderly patients, the prevalence of delirium ranges from 10 to $40 \%[3,12,13]$. Delirium is also associated with major adverse outcomes such as increased mortality, functional impairment, prolonged hospitalization, and increased cost of care [14-16]. Regardless of the evident clinical significance, delirium tends to be under-diagnosed and under-treated [17]. Therefore, early identification and effective psychiatric treatment of delirium is important in the comprehensive care of elderly hospitalized patients [18].

The management of delirium includes ensuring safety with environmental or supportive interventions, identifying and treating the cause of delirium, and enhancing the patient's functioning $[19,20]$. Regarding pharmacological intervention, antipsychotic medication has been considered as first-line pharmacotherapy of delirium except in the case by sedative or alcohol withdrawal $[19,20]$. Haloperidol, a typical antipsychotic, has continued to be the most frequently used antipsychotic drug [19-21] due to its effectiveness, relatively lesser sedative and hypotensive effects and fewer anticholinergic properties $[19,21]$. However, haloperidol may induce adverse side effects such as extrapyramidal symptoms (EPSs) $[19,21]$ or prolongation of the QTc interval and fatal arrhythmia such as torsade de pointes among patients with delirium [19,21-23]. EPSs are more likely to occur in elderly and seriously medically ill patients, who are also the most susceptible to delirium [24]. In addition, it may be difficult to distinguish agitation, a common behavioral symptom of delirium, from akathisia, a frequent EPSs induced by haloperidol $[25,26]$.

Recently, atypical antipsychotics such as risperidone, olanzapine, and quetiapine have been increasingly used to treat delirious patients due to the lower incidences of EPSs associated with these drugs [20,27-29]. Although a number of studies have been conducted to evaluate the efficacy or safety of atypical antipsychotics in the treatment of delirium, most of these reports have been in the form of case reports or open-label trials [30-32]. Only two placebo-controlled, randomized trials of atypical antipsychotics for the treatment of delirium have been reported [33,34]. Some randomized comparative trials assessing the efficacy of various antipsychotics in the treatment of delirium have been conducted in critical care units or consultation-liaison psychiatric services [26,28,32,35-39]. Five trials compared the efficacy between one atypical antipsychotic agent and haloperidol $[28,35,36,38,39]$ and two trials compared the effectiveness of two different atypical antipsychotics [26,37]. One trial assessed the comparative efficacy among two atypical antipsychotics and haloperidol [32]. Previous trials comparing the treatment response of atypical antipsychotics based on age ( $<70$ years old, $\geq 70$ years old) suggested that older age might predict a poor response to the treatment of delirium [26,40]. Recently, researchers in the field of psychiatry often divide older subjects into two groups (young-old and old-old), with an age of 74 being the cutoff point [41-43]. However, no previous research has compared the response rate to various atypical antipsychotics in the treatment of delirium based on this age grouping.

Although previous trials have reported that there was no significant difference in the efficacy between haloperidol and atypical antipsychotics in the treatment of delirium $[20,21,32,44]$, the reported data are not sufficient to form conclusions regarding the efficacy of various atypical antipsychotics compared to haloperidol. Only a few trials have considered age as a factor when comparing the response rates of atypical antipsychotics in the treatment of delirium $[26,40]$. To our knowledge, no previous trial has compared the efficacy and safety of haloperidol with more than two atypical antipsychotics in the treatment of delirium. For these reasons, we investigated the comparative efficacy and safety of haloperidol versus atypical antipsychotic medications in the treatment of delirium. The primary objective of this study was to compare the efficacy and safety of haloperidol versus three atypical antipsychotic medications (risperidone, olanzapine, and quetiapine) for patients with delirium. The secondary objective was to investigate whether response rate of haloperidol and three atypical antipsychotic medications differ depending on age, dividing the study cohort into two age groups, in the treatment of delirium.

\section{Methods \\ Subject}

The subjects enrolled in this study were patients presenting with a mental status change who were referred to a consultation-liaison psychiatric service at a tertiary level university hospital in Korea. To be enrolled in the study, subjects were required to meet the DSM-IV-TR [45] diagnostic criteria for delirium and to be older than 50 years. One hundred forty-six patients referred to consultationliaison psychiatric service for a mental status change were initially included in the screening process. Among them, 
130 patients who met the DSM-IV-TR [45] diagnostic criteria for delirium (77 percent) were screened for this study. Diagnosis of dementia and other psychiatric disorders was established by reviewing detailed clinical history and by obtaining information from reliable informants. Twentytwo patients with delirium were excluded. The reasons for exclusion were as follows: a diagnosis of dementia or comorbid psychiatric disorder $(\mathrm{N}=8)$, a terminal illness $(\mathrm{N}=7)$, a history of prolonged QTc interval $(\mathrm{N}=3)$, hearing loss $(\mathrm{N}=2)$, neuroleptic malignant syndrome $(\mathrm{N}=1)$, and use of antipsychotic medication before referral $(\mathrm{N}=1)$. Finally, 80 patients were included in this study after excluding patients $(\mathrm{N}=11)$ who refused to provide informed consent.

\section{Assessment}

The contributing cause of delirium for all participants was categorized using the Delirium Etiology Checklist (DEC) $[46,47]$. The DEC, which is a standardized checklist for attribution of delirium to all possible etiological causes, comprises 12 categories (drug intoxication, drug withdrawal, metabolic/endocrine disturbance, traumatic brain injury, seizures, intracranial infection, systemic infection, intracranial neoplasm, systemic neoplasm, cerebrovascular disease, organ insufficiency, other central nervous system disorders, and other systemic disease), each of which is rated on a five point scale for the degree of attribution to the episode of delirium, ranging from "ruled out/not present/not relevant" to "definite cause" [47].

The primary efficacy was evaluated by the Korean version of the Delirium Rating Scale-Revised-98 (DRS-K) [48]. The Delirium Rating Scale-Revised-98 (DRS-R-98) is an assessment tool designed for the evaluation of symptoms of delirium consisting of 16 items [49]. The DRS-R-98 is divided into two sections consisting of a 13-item severity scale and a 3-item diagnostic scale. The severity scales of DRS-R-98 include two subscales: non-cognitive (items 1-8) and cognitive (items 9-13) [50]. Each item on the severity scale is rated 0 to 3 points and each item in the diagnostic scale is rated from 0 to 2 or 3 points. The severity scale score ranges between 0 to 39 points, with a higher score indicating more severe delirium. The original validation study suggested cutoff scores for differential diagnosis from dementia or other psychiatric disorders of approximately 15 points on the severity scale [49]. Treatment response in this study was defined as $\geq 50 \%$ reduction from baseline in the severity scores of DRS-K in the same manner as a previous study comparing the effectiveness and safety of atypical antipsychotic medications in the treatment of delirium [26].

The secondary efficacy was evaluated by the Korean version of the Mini Mental Status Examination (K-MMSE) [51]. The Mini Mental Status Examination (MMSE) is a 30 point cognitive test for the bedside assessment of cognitive function [52]. The MMSE contains 19 items and the maximum score is 30 points (10 points for orientation, 6 points for verbal memory, 5 points for concentration and calculation, 5 points for language, 3 points for praxis, 1 point for visuospatial construction).

The safety measures involved reported adverse events and EPSs, evaluated on the basis of the Udvalg Kliniske Undersogelser (UKU) neurological side effect items (dystonia, rigidity, bradykinesia, tremor, and akathisia) [53].

All the subjects were evaluated at baseline and on the second, the fourth, and sixth days at the same time of day (PM 7:00-9:00).

\section{Procedure}

This study was a 6-day, prospective, comparative clinical observational study of haloperidol versus three atypical antipsychotics (risperidone, olanzapine, and quetiapine) for treatment of delirium. All subjects who fulfilled the criteria were assigned either haloperidol, risperidone, olanzapine, or quetiapine group depending on the clinical and empirical judgment of the clinician. The selection of antipsychotic drug being given and dose titration were performed by one of the investigators, and all the assessments were carried out by another investigator who was blind to the antipsychotic drug being administered.

\section{Dose and titration}

The initial starting dose was determined on the basis of age, degree of severity of delirium, and the general medical or postsurgical condition of the individual subject. The titration of dose was adjusted according to clinical judgment based on daily overall clinical impression of delirium over 6 days primarily, and was also modified depending on clinical assessments regarding the degree of improvement in delirium symptoms and the presence or absence of adverse events observed through serial assessments of DRS-K, K-MMSE, and UKU neurologic side effect items. A flexible dosing regimen (haloperidol: 0.5-10 mg, risperidone: $0.25-4 \mathrm{mg}$, olanzapine: $1-20 \mathrm{mg}$, quetiapine: 25-200 mg) was used. Because strict restriction of rescue medication in subjects with a poor general medical condition would have been ethically problematic, rescue intramuscular injections of haloperidol or lorazepam were allowed and recorded.

\section{Statistical analysis}

The data were analyzed using the Statistical Package for Social Scientists, version 18.0 (SPSS; Chicago, IL). Group comparisons of demographic characteristics, mean baseline DRS-K and K-MMSE scores, and the mean daily chlorpromazine equivalent dose were established using the chi-square test or Fisher's exact test for categorized variables and one-way analysis of variance (ANOVA) for continuous variables. In this longitudinal study, because 
some data were missing due to dropout or other reasons such as discharge, a linear mixed model $[54,55]$ was applied to compare changes in DRS-K and K-MMSE scores during treatment within each group and among the four groups. This model takes into account all available data, allows for missing value, and estimates fixed effects while adjusting for correlation due to repeated measurements on each subject [54-56]. Medication group, visit day, and dayby-group interaction were included as fixed effects. The group difference in treatment response and side effect profile were analyzed by the chi-square test or Fisher's exact test. In order to examine differences in treatment response depending on age, each patient's age was converted to a dichotomous variable with two levels (young-old: $<75$ years old, old-old: $\geq 75$ years old) [41-43]. All statistical analyses were two-tailed, with a significance level of probability set at 0.05 .

\section{Consent and approval}

The study design was approved by the Institutional Review Board and the ethics committees at Gangnam Severance Hospital, Yonsei University College of Medicine, Seoul, Korea. Written informed consent was obtained either from the subjects' primary caregivers or the legal representatives of the subjects prior to enrollment. Although it is the best way to seek consent from the subjects themselves in the clinical research, patients in the episode of delirium were unable to communicate meaningfully in most cases actually. Thus, we were obliged to seek consent from the primary caregivers or the legal representatives of the subjects. Prior to screening, the objective of this study and the pharmacological treatments available were explained to them. The primary caregivers or the legal representatives of subjects had the right to withdraw consent at any time during this study. Other ethical safeguards were also maintained during the study.

The other ethical safeguards maintained for the study is as follows: The etiological condition identified as cause of delirium was corrected and treated appropriately. Treatment for the primary medical or surgical condition of subjects was continued during study period in addition to use of the trial antipsychotic medications. Any medication which could cause or aggravate delirium was discontinued promptly since screening process of study began. Any medication that was not essential for the treatment of underlying condition was used minimally or stopped during the study period. Personal information of the subjects was stored at the separate disc space with password.

\section{Results}

Demographic characteristics and causes of delirium A total of 80 patients consisting of 36 men (45\%) and 44 women $(55 \%)$ were enrolled in this study. The mean age and years of education of the subjects were $71.8 \pm 11.5$ years and $7.5 \pm 5.6$ years, respectively. There were no significant differences in sex, age and years of education between the four groups. In regard to contributing etiological causes of delirium, the mean number of all possible causes per patient was about two (1.9 \pm 0.6$)$. Most patients had two $(\mathrm{N}=52,87.5 \%)$ or three $(\mathrm{N}=10$, $12.5 \%)$ contributing causes of delirium, and eighteen patients $(22.5 \%)$ had one definite cause associated with delirium. Significant difference was not observed on number of contributing causes between the four groups. The most common definite etiology of delirium in the study sample was metabolic-endocrine abnormality $(\mathrm{N}=$ 23). This was followed by organ insufficiency $(\mathrm{N}=16)$, systemic infection $(\mathrm{N}=14)$, systemic neoplasm $(\mathrm{N}=12)$, cerebrovascular cause $(\mathrm{N}=9)$, and others $(\mathrm{N}=6)$. A comparison of the frequency of each definite etiology of delirium among the four groups revealed that the differences among the four groups were not statistically significant (Table 1).

\section{Treatment group and clinical course of delirium}

All subjects $(\mathrm{N}=80)$ were assigned to receive either haloperidol $(\mathrm{N}=23)$, risperidone $(\mathrm{N}=21)$, olanzapine $(\mathrm{N}=18)$, or quetiapine $(\mathrm{N}=18)$ according to the clinical judgment of the investigator at the baseline assessment. Of the 80 subjects enrolled, 53 patients (66.2\%) completed this trial. The reasons for drop out included loss of follow up due to discharge from hospital $(\mathrm{N}=18)$, transfer to the intensive care unit $(\mathrm{N}=6)$, and withdrawal of consent $(\mathrm{N}=3)$. In the haloperidol group, nine of 23 patients dropped out during the study. Five subjects were discharged from the hospital, two subjects were transferred to the intensive care unit, and two subjects withdrew consent. In the risperidone group, seven of 21 subjects could not be evaluated after the fourth day because they were discharged from the hospital $(\mathrm{N}=5)$ or transferred to the intensive care unit $(\mathrm{N}=2)$. In the olanzapine group, five of 18 subjects did not complete the trial because of discharge from the hospital $(\mathrm{N}=4)$ or transfer to the intensive care unit $(\mathrm{N}=1)$. In the quetiapine group, six of 18 subjects dropped out due to discharge from the hospital $(\mathrm{N}=4)$, transfer to the intensive care unit $(\mathrm{N}=1)$, or withdrawal of consent $(\mathrm{N}=1)$. The difference in the dropout rate was not significant among the four groups $(\mathrm{p}=0.899)$. Excluding cases of dropout, the numbers of subjects who could not be evaluated at least once after the baseline assessment due to loss to follow-up or worsening medical condition were six in the haloperidol group, one in the risperidone group, two in the olanzapine group, and five in the quetiapine group.

The difference in the chlorpromazine equivalent dose between the four groups was not significant $(p=0.192)$. 
Table 1 Group comparisons of demographic characteristics, causes of delirium, medication, and number of subjects assessed

\begin{tabular}{|c|c|c|c|c|c|c|c|}
\hline \multicolumn{2}{|l|}{ Characteristic } & $\begin{array}{c}\text { Haloperidol } \\
\mathrm{N}=23\end{array}$ & $\begin{array}{c}\text { Risperidone } \\
\mathrm{N}=\mathbf{2 1}\end{array}$ & $\begin{array}{c}\text { Olanzapine } \\
\mathrm{N}=18\end{array}$ & $\begin{array}{l}\text { Quetiapine } \\
\qquad N=18\end{array}$ & $\begin{array}{c}\text { Total } \\
\mathrm{N}=80\end{array}$ & Sig. \\
\hline \multicolumn{2}{|l|}{ Age, year } & $74.0 \pm 9.9$ & $70.1 \pm 9.5$ & $69.5 \pm 15.9$ & $73.3 \pm 10.7$ & $71.8 \pm 11.5$ & 0.522 \\
\hline \multicolumn{2}{|l|}{ Education, year } & $5.8 \pm 4.5$ & $8.7 \pm 6.9$ & $8.5 \pm 6.4$ & $7.3 \pm 3.9$ & $7.5 \pm 5.6$ & 0.327 \\
\hline \multicolumn{2}{|l|}{ Gender, male } & $12(52.2)$ & $8(38.1)$ & $8(44.4)$ & $8(44.4)$ & $36(45)$ & 0.828 \\
\hline \multicolumn{2}{|c|}{ Number of contributing causes of delirium } & $1.8 \pm 0.5$ & $1.9 \pm 0.7$ & $1.9 \pm 0.4$ & $2.0 \pm 0.8$ & $1.9 \pm 0.6$ & 0.783 \\
\hline \multicolumn{8}{|l|}{ Definite cause of delirium } \\
\hline \multicolumn{2}{|l|}{ Metabolic/endocrine } & $6(26.0)$ & $8(38.0)$ & $4(22.2)$ & $5(27.7)$ & $23(28.7)$ & 0.759 \\
\hline \multicolumn{2}{|l|}{ Systemic infection } & $4(17.3)$ & $3(14.2)$ & $3(16.6)$ & $4(22.2)$ & 14(17.5) & 0.957 \\
\hline \multicolumn{2}{|l|}{ Systemic neoplasm } & $6(26.0)$ & $1(4.7)$ & $3(16.6)$ & $2(11.1)$ & 12(15.0) & 0.260 \\
\hline \multicolumn{2}{|l|}{ Cerebrovascular } & $3(13.0)$ & $3(14.2)$ & $0(0.0)$ & $3(16.6)$ & $9(11.2)$ & 0.328 \\
\hline \multicolumn{2}{|l|}{ Organ insufficiency } & $3(13.0)$ & $3(14.2)$ & $8(44.4)$ & $2(11.1)$ & 16(20.0) & 0.059 \\
\hline \multicolumn{2}{|l|}{ Others } & $1(4.3)$ & $3(14.2)$ & $0(0.0)$ & $2(11.1)$ & $6(7.5)$ & 0.354 \\
\hline \multicolumn{2}{|l|}{ Dose, mg/day } & $1.2 \pm 0.4$ & $1.1 \pm 0.3$ & $2.9 \pm 1.0$ & $47.9 \pm 17.1$ & & \\
\hline \multicolumn{2}{|c|}{ Chlorpromazine equivalent dose, mg/day } & $60.0 \pm 21.4$ & $56.3 \pm 16.8$ & $59.8 \pm 20.5$ & $63.9 \pm 22.8$ & $59.8 \pm 20.4$ & 0.192 \\
\hline \multicolumn{2}{|l|}{ Duration of medication, day } & $4.7 \pm 1.6$ & $5.1 \pm 1.3$ & $5.3 \pm 1.1$ & $4.8 \pm 1.7$ & $4.9 \pm 1.5$ & 0.655 \\
\hline \multirow[t]{4}{*}{ Number of subjects assessed, } & Baseline & 23(100.0) & $21(100.0)$ & 18(100.0) & 18(100.0) & 80(100.0) & \\
\hline & Day 2 & 18(78.2) & $21(100.0)$ & 18(100.0) & 15(83.3) & $72(90.0)$ & \\
\hline & Day 4 & 16(69.5) & 18(85.7) & 15(83.3) & $12(66.6)$ & $61(76.2)$ & \\
\hline & Day 6 & $14(60.8)$ & $14(66.6)$ & $13(72.2)$ & $12(66.6)$ & $53(66.2)$ & \\
\hline
\end{tabular}

Data were presented as mean $\pm \mathrm{SD}$ or $\mathrm{N}(\%)$.

Rescue intramuscular injection of haloperidol was used 13 times in seven subjects in the haloperidol group, 12 times in nine subjects in the risperidone group, eight times in four subjects in the olanzapine group, and 15 times in nine subjects in the quetiapine group. The mean doses of rescue intramuscular haloperidol were similar among the four groups (haloperidol: $1.4 \pm 2.3 \mathrm{mg}$, risperidone: $1.4 \pm 1.8 \mathrm{mg}$, olanzapine: $1.1 \pm 2.6 \mathrm{mg}$, quetiapine: $2.3 \pm 2.6$ $\mathrm{mg}, \mathrm{p}=0.419)$. Rescue intramuscular lorazepam injection was used once in one subject in the haloperidol group, twice in two subjects in the risperidone group, and four times in two subjects in the olanzapine group.

The mean duration of medication among all subjects was $4.9 \pm 1.5$ days. The mean duration of medication was not significantly different among the four groups (haloperidol: $4.7 \pm 1.6$ days, risperidone: $5.1 \pm 1.3$ days, olanzapine: $5.3 \pm 1.1$ days, quetiapine: $4.8 \pm 1.7$ days, $\mathrm{p}=0.655)$.

\section{Efficacy analysis}

In regards to both the primary and secondary efficacy measures of this study, the within-group effect was statistically significant in all groups. A significant serial decrease in the mean DRS-K severity score (Figure 1) and increase in the mean K-MMSE score (Figure 2) was observed in all groups during the study period.
The day-by-group interaction effect and between-group effect was not significant in any efficacy measures (Table 2).

The cognitive and non-cognitive subscale scores of the DRS-K decreased significantly over the study period in all groups ( $\mathrm{p}<0.001)$. However, the rate of reduction of either subscale score did not differ significantly among the four groups during the study period ( $\mathrm{p}=0.718, \mathrm{p}=0.918)$.

In terms of treatment response, there was no significant difference in the response rate among the four groups (haloperidol: 15/23, 65.2\%, risperidone: 14/21, 66.6\%, olanzapine: $12 / 18,66.6 \%$, and quetiapine: $13 / 18,72.2 \%$, $\mathrm{p}=0.969$ ). When response rate was compared according to demographic characteristics, no significant difference was noted according to sex $(p=0.886)$. Overall, the response rate was significantly lower in subjects over 75 years old $(15 / 32,46.8 \%)$ compared to those under 75 years old $(39 / 48,81.2 \%, p=0.001)$ (Figure 3$)$. Of note, the response rate to olanzapine was much lower in subjects over 75 years old $(2 / 7,28.5 \%)$ compared to those under 75 years old $(10 / 11,90.9 \%, p=0.013)$, while the response rates of the other three groups did not differ significantly between the two age groups $(\mathrm{p}>0.05)$ (Figure 3).

The difference in the mean baseline K-MMSE score among the four groups was not significant $(p=0.565)$. In contrast to the DRS-K severity score, the mean K-MMSE score increased serially from the baseline assessment in all groups (all $\mathrm{p}<0.001$ ). However, the rate of improvement 


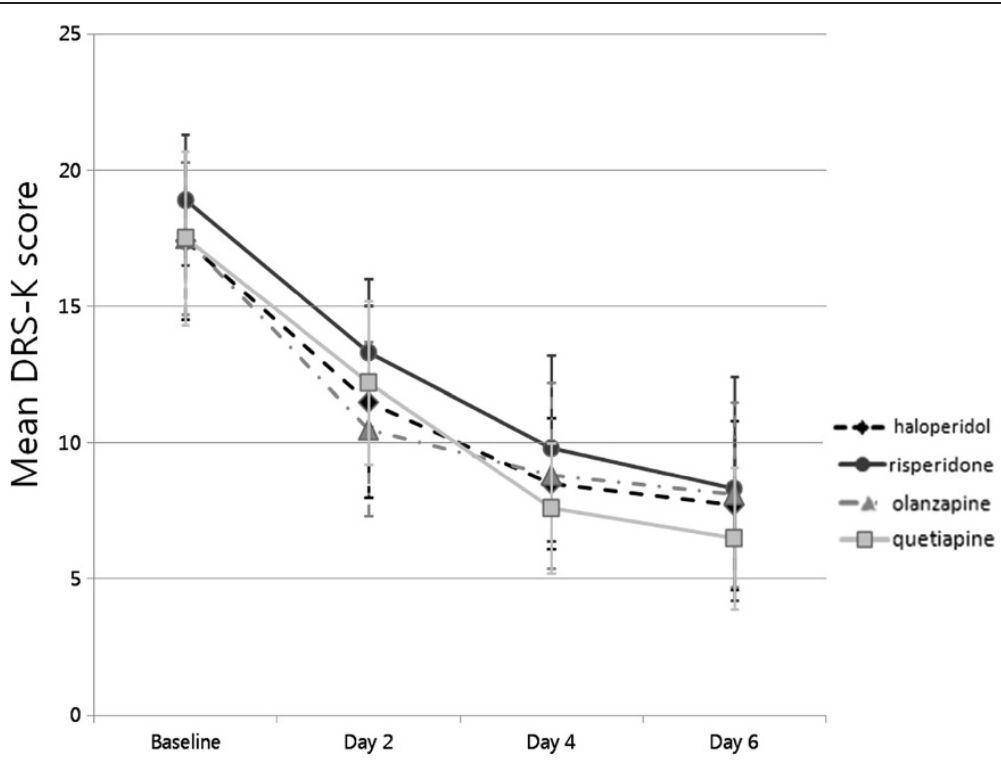

Figure 1 Serial changes in DRS-K severity scores in the four antipsychotic groups. Mean changes in DRS-K severity scores with $95 \%$ confidence intervals. In all antipsychotic groups, the mean DRS-K severity score decreased significantly over the study period (all p-values analyzed by linear mixed model statistics $<0.0001$ ). However, there were no significant differences in the degree of reduction in mean DRS-K severity score with time among the four groups ( $p$-values analyzed by linear mixed model statistics $=0.779$ ).

in the K-MMSE score did not differ significantly among the four groups $(\mathrm{p}=0.630)$.

\section{Safety analysis}

Overall, all subjects tolerated the four antipsychotics well. Fifteen $(18.8 \%)$ of the total subjects experienced some adverse events. Exacerbation of sedation or sleepiness was reported in four subjects in both the haloperidol and olanzapine groups, three subjects in the risperidone group, and two subjects in the quetiapine group. Rigidity was reported in two subjects in the haloperidol group, and one subject in each of the other three groups. Bradykinesia was reported in one subject in each of the haloperidol, risperidone, and olanzapine groups. Tremors were reported

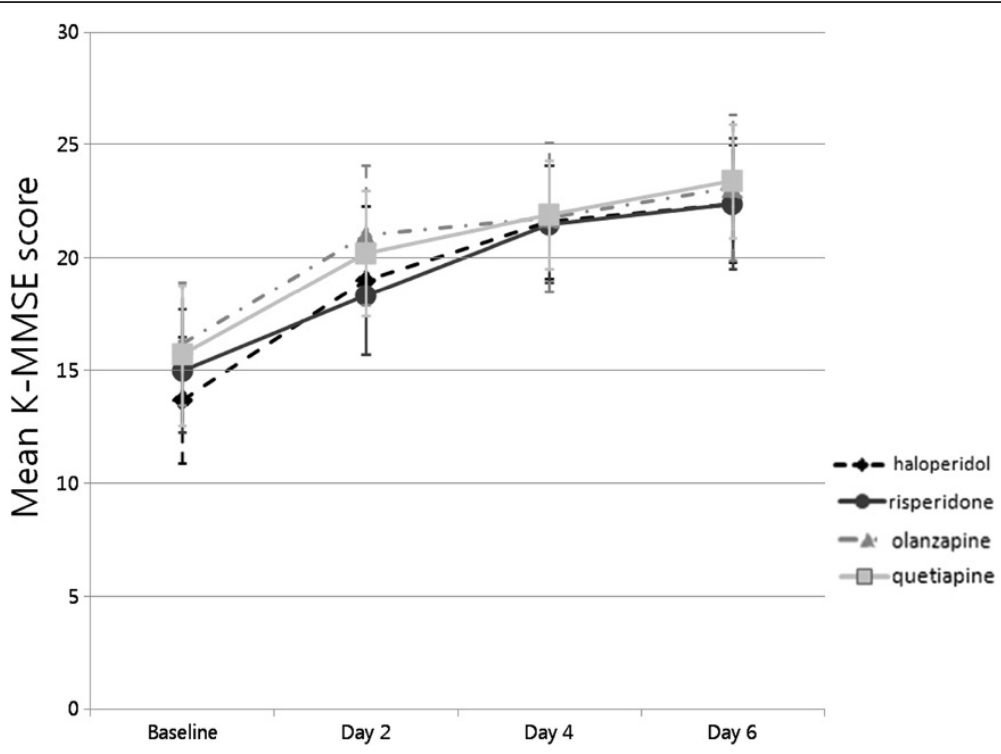

Figure 2 Serial changes in K-MMSE scores in the four antipsychotic groups. Mean changes in K-MMSE scores with 95\% confidence intervals. In all antipsychotic groups, the mean K-MMSE score increased significantly over the study period (all p-values analyzed by linear mixed model statistics $<0.0001)$. However, there were no significant differences in the degree of improvement in mean K-MMSE score with time among the four groups ( $p$-values analyzed by linear mixed model statistics $=0.630$ ). 
Table 2 Group comparisons of serial changes in DRS-K and K-MMSE scores

\begin{tabular}{|c|c|c|c|c|c|c|c|}
\hline Efficacy measures & & Haloperidol & Risperidone & Olanzapine & Quetiapine & Total & Sig. \\
\hline \multicolumn{8}{|l|}{ DRS-K } \\
\hline \multirow[t]{4}{*}{ Severity score } & Baseline & $17.4 \pm 6.7$ & $18.9 \pm 5.2$ & $17.5 \pm 5.7$ & $17.5 \pm 6.4$ & $17.8 \pm 6.0$ & $0.779^{\dagger}$ \\
\hline & Day 2 & $11.5 \pm 7.1$ & $13.3 \pm 5.8$ & $10.5 \pm 6.6$ & $12.2 \pm 5.4$ & $11.93 \pm 6.2$ & \\
\hline & Day 4 & $8.5 \pm 4.6$ & $9.8 \pm 6.7$ & $8.8 \pm 6.0$ & $7.6 \pm 3.7$ & $8.80 \pm 5.4$ & \\
\hline & Day 6 & $7.7 \pm 5.4$ & $8.3 \pm 7.1$ & $8.1 \pm 5.5$ & $6.5 \pm 4.0$ & $7.75 \pm 5.5$ & \\
\hline \multirow[t]{4}{*}{ Cognitive subscale score } & Baseline & $7.8 \pm 3.8$ & $8.7 \pm 3.4$ & $7.7 \pm 3.6$ & $8.1 \pm 3.2$ & $8.14 \pm 3.5$ & $0.718^{\dagger}$ \\
\hline & Day 2 & $5.7 \pm 3.9$ & $6.5 \pm 3.4$ & $5.0 \pm 3.0$ & $5.6 \pm 2.6$ & $5.76 \pm 3.3$ & \\
\hline & Day 4 & $4.3 \pm 2.4$ & $4.8 \pm 3.6$ & $4.2 \pm 3.2$ & $4.0 \pm 2.5$ & $4.43 \pm 3.0$ & \\
\hline & Day 6 & $4.0 \pm 2.9$ & $4.1 \pm 4.0$ & $4.2 \pm 2.7$ & $3.2 \pm 2.5$ & $3.94 \pm 3.1$ & \\
\hline \multirow[t]{4}{*}{ non-cognitive subscale score } & Baseline & $9.5 \pm 3.5$ & $10.1 \pm 3.0$ & $9.7 \pm 3.3$ & $9.4 \pm 4.2$ & $9.73 \pm 3.4$ & $0.918^{\dagger}$ \\
\hline & Day 2 & $5.7 \pm 3.5$ & $6.5 \pm 2.9$ & $5.5 \pm 3.8$ & $6.6 \pm 3.7$ & $6.11 \pm 3.4$ & \\
\hline & Day 4 & $4.1 \pm 2.6$ & $4.9 \pm 3.8$ & $4.6 \pm 3.5$ & $3.6 \pm 2.2$ & $4.41 \pm 3.1$ & \\
\hline & Day 6 & $3.7 \pm 2.8$ & $4.2 \pm 3.6$ & $3.9 \pm 3.5$ & $3.3 \pm 2.0$ & $3.81 \pm 3.0$ & \\
\hline \multicolumn{8}{|l|}{ K-MMSE score } \\
\hline & Baseline & $13.7 \pm 6.5$ & $15.0 \pm 5.8$ & $16.2 \pm 5.4$ & $15.7 \pm 6.3$ & $15.1 \pm 6.0$ & $0.630^{\dagger}$ \\
\hline & Day 2 & $19.0 \pm 6.7$ & $18.3 \pm 5.7$ & $21.0 \pm 6.2$ & $20.2 \pm 4.9$ & $19.5 \pm 5.9$ & \\
\hline & Day 4 & $21.3 \pm 4.7$ & $21.5 \pm 5.3$ & $21.8 \pm 5.8$ & $21.9 \pm 3.7$ & $21.6 \pm 4.9$ & \\
\hline & Day 6 & $22.4 \pm 4.4$ & $22.4 \pm 5.0$ & $23.1 \pm 5.3$ & $23.4 \pm 3.7$ & $22.8 \pm 4.6$ & \\
\hline
\end{tabular}

Data were presented as mean \pm SD.

t: $p$-values analyzed among groups by linear mixed model statistics.

Each day-by-group interaction was not significant in all efficacy measures.

(all p-values analyzed by linear mixed model statistics $>0.05$ ).

In all medication groups, the mean score of DRS-K severity, cognitive and non-cognitive subscale tended to decrease significantly over study period.

(all p-values analyzed by linear mixed model statistics $<0.0001$ ).

In all medication groups, the mean score of K-MMSE tended to increase significantly over the study period. (all p-values analyzed by linear mixed

model statistics $<0.0001$ ).

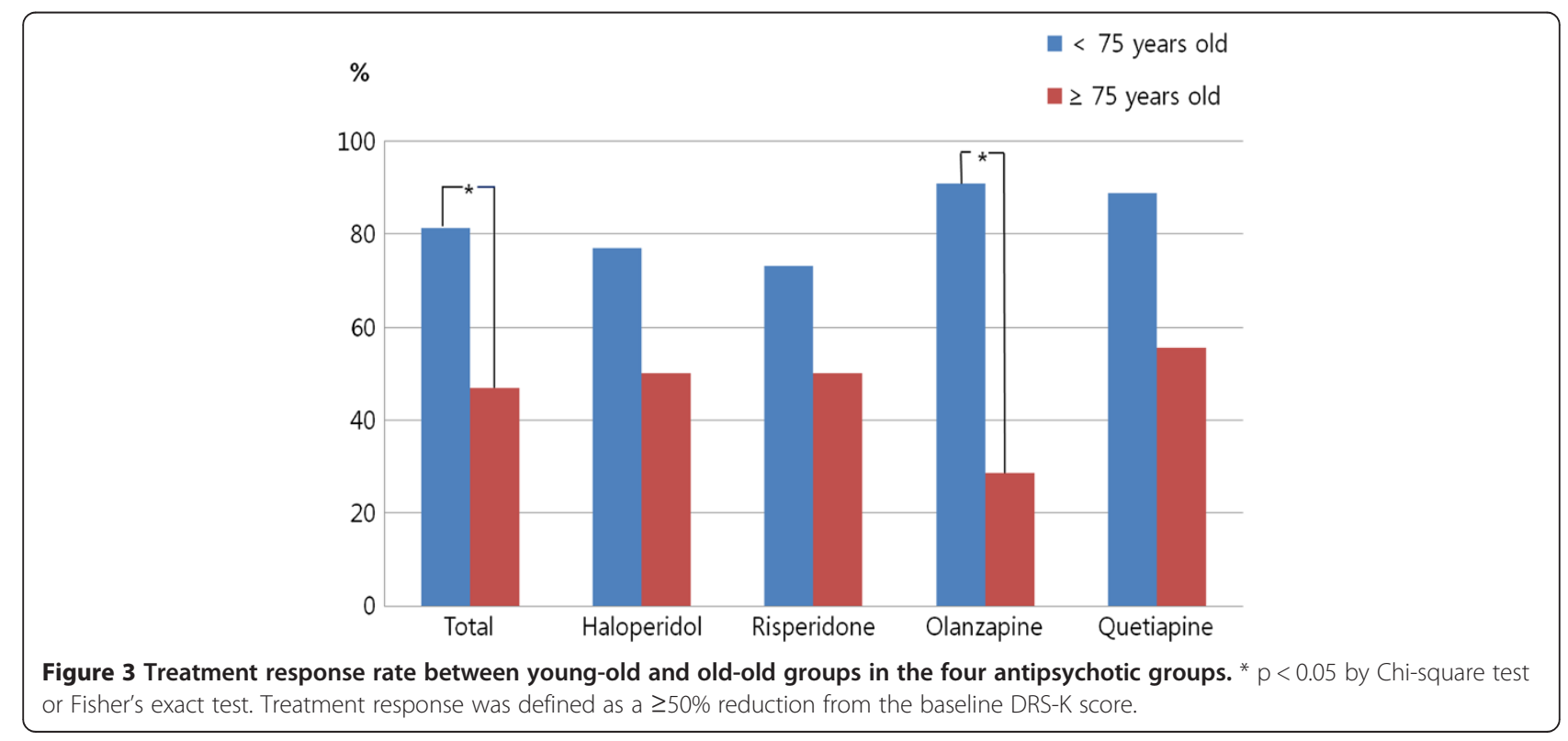


in three subjects in the haloperidol group, two subjects in the risperidone group, and one subject in each of the olanzapine and quetiapine groups. Akathisia was only reported in one subject in the haloperidol group. All extrapyramidal side effects were tolerable and mild in severity. When the number of subjects experiencing side effects was compared among the four groups, the difference was not statistically significant (Table 3).

\section{Discussion}

Recently, a number of researchers have reported that atypical antipsychotics may be as effective as haloperidol in treating delirium $[20,21,28,32,35,36,38,39]$. Risperidone, olanzapine, and quetiapine have been increasingly used for pharmacologic intervention of delirium [20,26-29]. Previous researches have shown that the efficacy of risperidone and olanzapine is not different from that of haloperidol in the treatment of delirium $[28,32,35,36,44,57-59]$. Quetiapine has been reported to be as efficacious as haloperidol [58] and to reduce the severity of the symptoms of delirium more rapidly than placebo [33]. To date, most randomized comparative trials of atypical antipsychotics in the treatment of delirium have compared the efficacy of one atypical antipsychotic agent and haloperidol $[28,35,36,38,39]$ or two different atypical antipsychotics [26,37]. Only one randomized comparative study has compared the efficacy of two different atypical antipsychotics and haloperidol [32]. To our knowledge, this study is the first trial to compare the efficacy and safety of haloperidol versus three atypical antipsychotics. In the present study, haloperidol, risperidone, olanzapine and quetiapine were equally effective in improving the symptoms of delirium. There was no significant difference in the rate of reduction of DRS-K severity score and improvement of K-MMSE score with time among the four groups. Recently, one comparative efficacy study of haloperidol, risperidone, and olanzapine showed that risperidone and olanzapine were as efficacious as haloperidol in treating delirium [32]. Our result supports the findings of previous researches with regard to the comparative efficacy of haloperidol versus three atypical antipsychotics in managing symptoms of delirium
[28,32,35,36,44,57-59]. The mean daily doses of risperidone, olanzapine, and quetiapine were not largely different from those of previous studies [26,32,35,36,57,60-62]. This finding also suggests that a relatively low dose of atypical antipsychotics may be effective in managing the symptoms of delirium $[26,28,32,36]$.

There have been no previous studies to have assessed the difference in the efficacy of atypical antipsychotics in terms of the cognitive and non-cognitive subscale scores of the DRS-R-98, with the exception of one placebo, controlled trial [33]. The group difference was not significant over this study period in terms of the rate of reduction of the cognitive and non-cognitive subscale scores of the DRS-K. In fact, improvement of cognitive and non-cognitive symptoms of delirium could occur naturally [33], due to nonspecific environmental care [63] or to treating the underlying etiologies of delirium [21]. Nevertheless, our findings might be meaningful in that the effectiveness of haloperidol versus three atypical antipsychotics was compared in the two different symptom domains of delirium at the same time in a real clinical setting.

The demographic characteristics of the subjects enrolled in this study were not significantly different from those of subjects in previous studies [32,36,37]. In regards to the causes of delirium, most subjects had more than one contributing cause of delirium. The most common definite cause of delirium was metabolic or endocrine disturbance, a finding which was similar to that of previous studies of patients with delirium referred to a consultationliaison psychiatric service [32,47].

In the present study, the response rate to olanzapine was poor in subjects over 75 years old compared to those under 75 years old. However, the response rate to the other three antipsychotics was not significantly different between age groups. A previous study reported that old age was associated with poorer response to olanzapine in hospitalized cancer patients with delirium [40], while another study reported that the response rate of olanzapine was similar depending on age, but that the response rate to risperidone was much lower in an older age group [26]. The major neurotransmitter hypothesized to be involved

Table 3 Group comparisons of frequency of UKU side effect rating scale items

\begin{tabular}{|c|c|c|c|c|c|c|}
\hline Side effects & Haloperidol & Risperidone & Olanzapine & Quetiapine & Total & Sig. \\
\hline Sedation/Sleepiness & $4(17.3)$ & $3(14.2)$ & $4(22.2)$ & $2(11.1)$ & $13(16.2)$ & 0.838 \\
\hline Dystonia & $0(0.0)$ & $0(0.0)$ & $0(0.0)$ & $0(0.0)$ & $0(0.0)$ & - \\
\hline Rigidity & $2(8.7)$ & $1(4.7)$ & $1(5.5)$ & $1(5.5)$ & $5(6.2)$ & 1.000 \\
\hline Bradykinesia & $1(4.3)$ & $1(4.7)$ & $1(5.5)$ & $0(0)$ & $3(3.7)$ & 1.000 \\
\hline Tremor & $3(13.0)$ & $2(9.5)$ & $1(5.5)$ & $1(5.5)$ & $7(8.7)$ & 0.869 \\
\hline Akathisia & $1(4.3)$ & $0(0)$ & $0(0)$ & $0(0)$ & $1(1.2)$ & 1.000 \\
\hline Total number of subjects reporting side effects & $5(21.7)$ & $4(19.0)$ & $4(22.2)$ & $2(11.1)$ & 15(18.7) & 0.857 \\
\hline
\end{tabular}

Data were presented as $\mathrm{N}(\%)$. 
in delirium is acetylcholine, and several studies have reported that a variety of delirium-inducing factors are associated with decreased acetylcholine activity in the brain [64]. Actually, many medications with anticholinergic side effects can induce or aggravate delirium [21]. In regards to the pharmacological profile, olanzapine is known to have a significant affinity for muscarinic receptors and to induce relatively more anticholinergic adverse effects than the other three antipsychotics $[65,66]$. Age-related differences in susceptibility to anticholinergic adverse effects might have affected the response rate in the olanzapine group. Another possibility for the reduced effectiveness of olanzapine in the older age group is that some of the patients may have had undiagnosed dementia. In addition, this might be related to differences in the general underlying medical condition, as the frequency of organ insufficiency was relatively higher in the olanzapine group than in the other three groups. These results suggest that advanced age is not only a risk factor $[21,64,67]$ for delirium, but also may be a predictor of poor response to delirium treatment with atypical antipsychotics. Therefore, further investigation of the impact of age on treatment response is required.

There were no significant group differences in the number of subjects experiencing adverse events or in the type of adverse events. Although previous review articles have suggested that atypical antipsychotics are safe, with a lower rate of adverse events compared to haloperidol in the treatment of delirium [20,21], a Cochrane review reported that haloperidol at a low dosage ( $<3.5 \mathrm{mg} /$ day) was safe, with a similar frequency of adverse events compared to atypical antipsychotics [44]. In this study, the mean daily dose of haloperidol was relatively low $(1.2 \pm 0.4 \mathrm{mg} /$ day $)$ and the total duration of medication was relatively short. Thus, the results of the present study suggest that a low dose of haloperidol is safe and does not show a greater frequency of EPSs [44] compared to atypical antipsychotics over a relatively short period of treatment.

This study has several limitations: (a) Our study did not include a placebo control group. The absence of comparative placebo control group with active treatment groups limited the interpretation of our findings; (b) The use of empirical judgment of clinician to assign antipsychotic medications without randomization might be important source of bias and limit our findings. However, we found no significant difference in demographic and clinical characteristics among four groups; (C) Heterogeneity of study population including medical and surgical patients could be a major limiting factor in the interpretation of our main findings even though there was no significant difference in clinical characteristics among four groups; (d) Since the consultation-liaison psychiatric service might recruit a skewed patient cohort most likely to have active psychiatric symptoms, this should be acknowledged as a source of bias; (e) Since this was a pilot study, we did not consider sample size as a requirement for carrying out the proposed objectives and the small subject numbers in each group might limit the strength of the conclusions from our work. Thus, further studies with a larger number of subjects are needed to test our findings; (f) Although we made efforts to exclude patients with dementia by reviewing detailed clinical history and by obtaining information from reliable informants, dementia was not evaluated by a standardized screening instrument. Given that the number of subjects with dementia was relative low $(\mathrm{N}=8)$ in screening process, subjects with dementia might be misclassified; (g) Although the rater was blind to which study drug was being administered, as the rater knew that all subjects were receiving active treatment, the ratings could have been affected; (h) Confounding factors associated with rescue medication could not be rigidly controlled due to ethical considerations. The permission to use rescue medication might not have seriously affected the results of this study because the total mean dose of intramuscular rescue injection of haloperidol was not significantly different among the four groups. If the dosing titration of the study drugs had been escalated more rapidly, the need for rescue medication could have been decreased; (i) The dropout rate was relatively high, and the missing data caused by dropouts could affect the result of this study. In order to overcome this limitation, we used a linear mixed model, in which all available data can be included and missing data can be appropriately addressed [54,55]. By using the average area under each subject's rating scale trajectory, we could compare treatment groups across whole study period; (i) The safety analysis was focused only on extrapyramidal side effects and could not evaluate other potential adverse events, such as QTc prolongation or arrhythmia associated with use of antipsychotic drugs [19,21-23]. Overall, six patients were transferred to the intensive care unit due to aggravation of an underlying medical or postsurgical condition during the study. Given that potential adverse effects of antipsychotic drugs, which had not been captured by data, might contribute to aggravation of underlying medical conditions, transfer to the intensive care unit during the study needs to be considered as a potential adverse effect of antipsychotic medications; (B) Changes in the various medical or surgical conditions of the study subjects might have affected the symptom severity of delirium, regardless of the use of antipsychotics; (1) Finally, as the symptoms of delirium can fluctuate and improve irrespective of the treatment given [33], the findings of our study must be understood in the background of these limitations. Regardless of these limitations, the results of the present study could provide 
important clinical information regarding the usefulness of commonly prescribed antipsychotics in the treatment of delirium with various underlying etiologies in a tertiary hospital setting.

\section{Conclusions}

In conclusion, the atypical antipsychotics risperidone, olanzapine, and quetiapine and low dose haloperidol were equally effective and safe in the treatment of delirium. The treatment response rate for the only olanzapine group was significantly lower in subjects over 75 years old than in subjects under 75 years old. The factor of age needs to be considered in the choice of antipsychotic medication for the treatment of delirium. Further prospective randomized placebo controlled trials of a larger patient group with delirium should be carried out to test the generalizability of our findings.

\section{Abbreviations}

EPSs: Extrapyramidal symptoms; DSM-IV-TR: Diagnostic and statistical manual of mental disorders-iv-text revision; DEC: Delirium etiology checklist; DRS-K: Korean version of the delirium rating scale-revised-98; DRS-R-98: Delirium rating scale-revised-98; K-MMSE: Korean version of the mini mental status examination; MMSE: Mini mental status examination; UKU: Udvalg Kliniske Undersogelser; SPSS: Statistical package for social scientists; ANOVA:

One-way analysis of variance.

\section{Competing interests}

The result of this study was submitted as a research poster in the 16th international congress of international psychogetriatric association in Seoul.

\section{Authors' contributions}

All authors participated in the design of the trial and read and approved the final manuscript.

Received: 11 January 2013 Accepted: 23 September 2013

Published: 30 September 2013

\section{References}

1. Inouye SK, Charpentier PA: Precipitating factors for delirium in hospitalized elderly persons: predictive model and interrelationship with baseline vulnerability. JAMA 1996, 275(11):852-857.

2. Inouye SK: Delirium in hospitalized older patients. Clin Geriatr Med 1998, 14(4):745-764

3. Fong TG, Tulebaev SR, Inouye SK: Delirium in elderly adults: diagnosis, prevention and treatment. Nat Rev Neurol 2009, 5(4):210-220.

4. Dyer $\mathrm{CB}$, Ashton $\mathrm{CM}$, Teasdale TA: Postoperative delirium: a review of 80 primary data-collection studies. Arch Intern Med 1995, 155(5):461-465.

5. Marcantonio ER, Goldman L, Orav EJ, Cook EF, Lee TH: The association of intraoperative factors with the development of postoperative delirium. Am J Med 1998, 105(5):380-384.

6. Minagawa H, Uchitomi Y, Yamawaki S, Ishitani K: Psychiatric morbidity in terminally ill cancer patients. A prospective study. Cancer 1996, 78(5):1131-1137.

7. Pereira J, Hanson J, Bruera E: The frequency and clinical course of cognitive impairment in patients with terminal cancer. Cancer 1997, 79(4):835-842.

8. Lawlor PG, Gagnon B, Mancini IL, Pereira JL, Hanson J, Suarez-Almazor ME, Bruera ED: Occurrence, causes, and outcome of delirium in patients with advanced cancer: a prospective study. Arch Intern Med 2000, 160(6):786-794.

9. Burns A, Gallagley A, Byrne J: Delirium. J Neurol Neurosur Ps 2004, 75(3):362-367.

10. Jain G, Chakrabarti S, Kulhara P: Symptoms of delirium: an exploratory factor analytic study among referred patients. Gen Hosp Psychiatry 2011, 33(4):377-385.
11. Gupta N, de Jonghe J, Schieveld J, Leonard M, Meagher D: Delirium phenomenology: what can we learn from the symptoms of delirium? J Psychosom Res 2008, 65(3):215-222.

12. Lipowski ZJ: Delirium (acute confusional states). JAMA (Chicago, III) 1987, 258(13):1789-1792.

13. Inouye SK: Delirium in older persons. N Engl J Med 2006, 354(11):1157-1165.

14. Ely EW, Shintani A, Truman B, Speroff T, Gordon SM, Harrell FE, Inouye SK, Bernard GR, Dittus RS: Delirium as a predictor of mortality in mechanically ventilated patients in the intensive care unit. JAMA (Chicago, III) 2004, 291(14):1753-1762.

15. McCusker J, Cole MG, Dendukuri N, Belzile E: Does delirium increase hospital stay? J Am Geriatr Soc 2003, 51(11):1539-1546.

16. Siddiqi N, House AO, Holmes JD: Occurrence and outcome of delirium in medical in-patients: a systematic literature review. Age Ageing 2006, 35(4):350-364

17. Kean J, Ryan K: Delirium detection in clinical practice and research: critique of current tools and suggestions for future development. J Psychosom Res 2008, 65(3):255-259.

18. Pae C, Marks DM, Han C, Patkar A, Masand P: Delirium: where do we stand? Curr Psychiatry Rep 2008, 10(3):240-248.

19. Lacasse H, Perreault M, Williamson DR: Systematic review of antipsychotics for the treatment of hospital-associated delirium in medically or surgically ill patients. Ann Pharmacother 2006, 40(11):1966-1973.

20. Grover S, Mattoo SK, Gupta N: Usefulness of atypical antipsychotics and choline esterase inhibitors in delirium: a review. Pharmacopsychiatry 2011, 44(2):43-54

21. Ozbolt LB, Paniagua MA, Kaiser RM: Atypical antipsychotics for the treatment of delirious elders. J Am Med Dir Assoc 2008, 9(1):18-28.

22. Metzger E, Friedman R: Prolongation of the corrected QT and torsades de pointes cardiac arrhythmia associated with intravenous haloperidol in the medically ill. J Clin Psychopharmacol 1993, 13(2):128-132.

23. Glassman AH, Bigger JT Jr: Antipsychotic drugs: prolonged QTc interval, torsade de pointes, and sudden death. Am J Psychiatry 2001 158(11):1774-1782

24. Casey D: Acute extrapyramidal syndrome. Washington, DC: Contemporary Use in the Treatement of Schizophrenia American Psychiatric Press; 1995:535-550.

25. Breitbart W, Alici Y: Agitation and delirium at the end of life: "We couldn't manage him". JAMA (Chicago, III) 2008, 300(24):2898-2910. E2891.

26. Yoo J, Lee S, Kim S, Bae K, Yang S, Kim J, Shin I, Yoon J: Risperidone versus olanzapine for the treatment of delirium. Hum Psychopharm 2010, 25(4):298-302.

27. Schwartz TL, Masand PS: The role of atypical antipsychotics in the treatment of delirium. Psychosomatics 2002, 43(3):171-174.

28. Skrobik YK, Bergeron N, Dumont M, Gottfried SB: Olanzapine vs haloperidol: treating delirium in a critical care setting. Intens Care Med 2004, 30(3):444-449.

29. Pae CU, Lee SJ, Lee CU, Lee C, Paik IH: A pilot trial of quetiapine for the treatment of patients with delirium. Hum Psychopharmacol 2004, 19(2):125-127

30. Peritogiannis V, Stefanou E, Lixouriotis C, Gkogkos C, Rizos DV: Atypical antipsychotics in the treatment of delirium. Psychiat Clin Neuros 2009, 63(5):623-631

31. Bourne RS, Tahir TA, Borthwick M, Sampson EL: Drug treatment of delirium: past, present and future. J Psychosom Res 2008, 65(3):273-282.

32. Grover S, Kumar V, Chakrabarti S: Comparative efficacy study of haloperidol, olanzapine and risperidone in delirium. J Psychosom Res 2011, 71(4):277-281.

33. Tahir TA, Eeles E, Karapareddy V, Muthuvelu P, Chapple S, Phillips B, Adyemo T, Farewell D, Bisson Jl: A randomized controlled trial of quetiapine versus placebo in the treatment of delirium. J Psychosom Res 2010, 69(5):485-490.

34. Devlin JW, Roberts RJ, Fong J, Skrobik Y, Riker R, Hill NS, Robbins T, Garpestad E: Efficacy and safety of quetiapine in critically ill patients with delirium: a prospective, multicenter, randomized, double-blind, placebocontrolled pilot study. Crit Care Med 2010, 38(2):419-427.

35. Kim J, Jung I, Han C, Cho S, Kim L, Kim S, Lee B, Lee H, Kim Y: Antipsychotics and dopamine transporter gene polymorphisms in delirium patients. Psychiat Clin Neuros 2005, 59(2):183-188.

36. Han C, Kim Y: A double-blind trial of risperidone and haloperidol for the treatment of delirium. Psychosomatics 2004, 45(4):297-301.

37. Lee K, Won W, Lee H, Kweon Y, Lee CT, Pae C, Bahk W: Amisulpride versus quetiapine for the treatment of delirium: a randomized, open prospective study. Int Clin Psychopharm 2005, 20(6):311-314. 
38. $\mathrm{Hu} H$, Deng $\mathrm{W}$, Yang $\mathrm{H}$ : A prospective random control study comparison of olanzapine and haloperidol in senile delirium. Chongqing Med J 2004, 8:1234-1237.

39. Hu H, Deng W, Yang H, Liu Y: Olanzapine and haloperidol for senile delirium: a randomized controlled observation. Chinese J Clin Rehabil 2006, 10(42):188-190.

40. Breitbart W, Tremblay A, Gibson C: An open trial of olanzapine for the treatment of delirium in hospitalized cancer patients. Psychosomatics 2002, 43(3):175-182

41. Roose SP, Sackeim HA, Krishnan KR, Pollock BG, Alexopoulos G, Lavretsky H, Katz IR, Hakkarainen $\mathrm{H}$ : Antidepressant pharmacotherapy in the treatment of depression in the very old: a randomized, placebo-controlled trial. Am J Psychiat 2004, 161(11):2050-2059.

42. Cheng S, Yu EC, Lee SY, Wong JY, Lau KH, Chan LK, Chan H: The geriatric depression scale as a screening tool for depression and suicide ideation: a replication and extention. Am J Geriat Psychiat 2010, 18(3):256-265.

43. Paraschakis A, Douzenis A, Michopoulos I, Christodoulou C, Vassilopoulou K, Koutsaftis F, Lykouras L: Late onset suicide: distinction between "young-old" vs. "old-old" suicide victims. How different populations are they? Arch Gerontol Geriat 2012, 54(1):136-139.

44. Lonergan E, Britton AM, Luxenberg J, Wyller T: Antipsychotics for delirium. Cochrane Database Syst Rev 2007, 2, CD005594.

45. American Psychiatric Association., American Psychiatric Association. Task Force on DSM-IV: Diagnostic and statistical manual of mental disorders: DSM-IV-TR. 4th edition. Washington, DC: American Psychiatric Association; 2000.

46. Yudofsky SC, Hales RE, American Psychiatric Publishing: The American psychiatric publishing textbook of neuropsychiatry and behavioral neurosciences. 5th edition. Washington, DC: American Psychiatric Pub; 2008.

47. Grover S, Kate N, Agarwal M, Mattoo SK, Avasthi A, Malhotra S, Kulhara P, Chakrabarti S, Basu D: Delirium in elderly people: a study of a psychiatric liaison service in north India. Int Psychogeriatr 2012, 24(1):117-127.

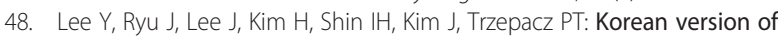
the delirium rating scale-revised-98: reliability and validity. Psychiat Invest 2011, 8(1):30-38

49. Trzepacz PT, Mittal D, Torres R, Kanary K, Norton J, Jimerson N: Validation of the delirium rating scale-revised-98: comparison with the delirium rating scale and the cognitive test for delirium. J Neuropsych Clin N 2001, 13(2):229-242

50. Meagher DJ, Leonard M, Donnelly S, Conroy M, Adamis D, Trzepacz PT: A longitudinal study of motor subtypes in delirium: relationship with other phenomenology, etiology, medication exposure and prognosis. J Psychosom Res 2011, 71(6):395-403.

51. Kang YND, Hahn S: A validity study on the Korean mini-mental state examination (K-MMSE) in dementia patients. J Korean Neurol Assoc 1997, 15(2):300-308

52. Folstein MF, Folstein SE, McHugh PR: Mini-mental state: a practical method for grading the cognitive state of patients for the clinician. J Psychiat Res 1975, 12(3):189-198.

53. Lingjaerde $O$, Ahlfors UG, Bech P, Dencker SJ, Elgen K: The UKU side effect rating scale: a new comprehensive rating scale for psychotropic drugs and a cross-sectional study of side effects in neuroleptic-treated patients. Acta Psychiatr Scand Supp/ 1987, 334:1-100.

54. Brown H, Prescott R: Applied mixed models in medicine. Chichester: Wiley; 1999.

55. Adamis D: Statistical methods for analysing longitudinal data in delirium studies. Int Rev Psychiatry 2009, 21(1):74-85.

56. Adamis D, Morrison C, Treloar A, Macdonald AJ, Martin FC: The performance of the clock drawing test in elderly medical inpatients: does it have utility in the identification of delirium? J Geriatr Psychiatry Neurol 2005, 18(3):129-133

57. Liu C, Juang Y, Liang H, Lin N, Yeh E: Efficacy of risperidone in treating the hyperactive symptoms of delirium. Int Clin Psychopharm 2004, 19(3):165-168.

58. Schwartz TL, Masand PS: Treatment of delirium with Quetiapine Prim Care Companion J Clin Psychiat 2000, 2(1):10-12.

59. Sipahimalani A, Masand PS: Olanzapine in the treatment of delirium. Psychosomatics 1998, 39(5):422-430.

60. Sasaki Y, Matsuyama T, Inoue S, Sunami T, Inoue T, Denda K, Koyama T: A prospective, open-label, flexible-dose study of quetiapine in the treatment of delirium. J Clin Psychiat 2003, 64(11):1316-1321.
61. Omura K, Amano N: Clinical experience of quetiapine in 24 elderly patients with delirium. Psychogeriatrics 2003, 3(2):69-72.

62. Gupta N, Sharma P, Mattoo SK: Effectiveness of risperidone in delirium. Can J Psychiat 2005, 50(1):75-75.

63. Lundstrom M, Edlund A, Karlsson S, Brannstrom B, Bucht G, Gustafson Y: A multifactorial intervention program reduces the duration of delirium, length of hospitalization, and mortality in delirious patients. J Am Geriatr Soc 2005, 53(4):622-628.

64. Sadock BJ, Kaplan HI, Sadock VA: Kaplan \& Sadock's synopsis of psychiatry: behavioral sciences/clinical psychiatry. 10th edition. Philadelphia: Wolter Kluwer/Lippincott Williams \& Wilkins; 2007.

65. Gardner DM, Baldessarini RJ, Waraich P: Modern antipsychotic drugs: a critical overview. Can Med Assoc J; CMAJ 2005, 172(13):1703-1711.

66. Chew ML, Mulsant BH, Pollock BG, Lehman ME, Greenspan A, Kirshner MA, Bies R, Kapur S, Gharabawi G: A model of anticholinergic activity of atypical antipsychotic medications. Schizophrenia Res 2006, 88(1-3):63-72.

67. Katz PR, Grossberg GT, Potter JF, Solomon DH: Geriatrics syllabus for specialists. New York: American Geriatrics Society; 2002.

doi:10.1186/1471-244X-13-240

Cite this article as: Yoon et al:: Efficacy and safety of haloperidol versus atypical antipsychotic medications in the treatment of delirium. BMC Psychiatry 2013 13:240.

\section{Submit your next manuscript to BioMed Central and take full advantage of:}

- Convenient online submission

- Thorough peer review

- No space constraints or color figure charges

- Immediate publication on acceptance

- Inclusion in PubMed, CAS, Scopus and Google Scholar

- Research which is freely available for redistribution 